\title{
Addendum to the checklist of the Aculeata fauna of Hungary (Aculeata: Apoidea s. 1.)
}

\author{
JÓZAN ZsOLT
}

H-7453 Mernye, Rákóczi F. u. 5., Hungary, jozan.zsolt@citromail.hu

JózAn, Zs: Addendum to the checklist of the Aculeata fauna of Hungary (Aculeata: Apoidea s. l.).

Abstract: In this paper, the author supplements the checklist of the Hungarian Aculeata fauna with new records for the Hungarian Aculeata fauna (JózAN 2011).

Keywords: Hymenoptera, Aculeata, supplement checklist, Hungary

In this paper, the author completes a previously published checklist of Aculeata species (JózAN 2011) from Hungary. Some species have been left out of the checklist and some new records for the fauna have also been detected in Hungary.

Together with the previously listed species (JózAN 2011), the number of species known from the territory of Hungary: Apoidea: Anthophila 711, Apoidea: Spheciformes 312

Abbreviations: $\mathrm{A}=$ Great Hungarian Plain, $\mathrm{Dd}=$ Transdanubian Hills, $\mathrm{Dk}=$ Transdanubian Mountains, Ék = North Hungarian Mountains, Nym = West Hungary.

\section{Species not included in the previous checklist:}

\section{Crabronidae}

Pemphredon lugens Dahlbom, 1842 - Dd, Dk, Ék, Nym (Bajári 1957, TANÁcs \& JóZAN 1993, JóZAN 1998, 2000a, 2006)

Pemphredon lugubris (Fabricius, 1793) - A, Dd, Dk, Ék (BAJÁRI 1957, TANÁCs \& JóZAN 1993, JóZAN 1998, 2000a, 2006)

Polemistus abnormis (Kohl, 1888) - Dd, Dk (Józan 1992, 1988, 2000a)

\section{Apidae}

Nomada emarginata Morawitz, 1877 - Dd, Dk, Nym (Móczár \& SchwarCz 1968, JóZAN 2000b, JóZAN 2002b)

\section{Megachilidae}

Anthidium nanum Mocsáry, 1879 (lituratum sensu Móczár 1958) - A, Dd, Dk, Ék (MóczÁR 1956)

\section{Species have been detected since 2011}

\section{Crabronidae}

Passaloecus borealis Dahlbom1844 - Dd (JózAn 2018)

Passaloecus brevilabris Merisuo, 1937 - Dd (JózAn 2018)

Pseudomicroides zimini (Gussakovkij, 1952) - Middle Hungary (BoGusch 2014) 


\title{
Sphecidae
}

Sceliphron caementarium (Drury, 1773) - A, Dd (VAS \& JóZAN 2014)

\author{
Apidae \\ Epeolus tarsalis Morawitz, 1874 - Dd, Dk (Bogusch \& HaDRaVA 2018) \\ Epeolus transitorius Eversmann, 1852 - A (Bogusch \& HADRAVA 2018) \\ Nomada moeschleri Alfken, 1913 - Dd (JóZAN 2018)
}

\section{Megachilidae}

Megachile sculpturalis Smith, 1853 - Ék (Kovícs 2015), A, Dk (unpublished localities, specimens are housed in the Rippl-Rónai Museum, Kaposvár.

\section{Melittidae}

Dasypoda morawitzi Radchenko, 2016 - A, Dd, Dk (JózAN 2018)

\section{References}

BAJÁRI, E. 1957: Kaparódarázs alkatúak I. - in: Magyarország Állatvilága (Fauna Hungariae) XIII/7: 1-117.

Bogusch, P. 2014: Filogeneze a ekologie žhadlových blanokřidlých (Hymenoptera: Aculeata), Habilitačni práce. - Masarykova univerzita Prirodovecka fakulta, Brno pp. 1-49.

Bogusch, P. \& Hadrava, J. 2018: European bees of the genera Epeolus Latreille, 1802 and Tiepeolus Robertson, 1901 (Hymenoptera: Apidae: Nomadinae: Epeolini): taxonomy, identification key, distribution, and ecology. - Zootaxa 4437(1): 001-060.

JózAN, Zs. 1992: A Zselic darázsfaunájának (Hymenoptera, Aculeata) állatföldrajzi és ökofaunisztikai vizsgálata. - Somogyi Múzeumok Közleményei 9: 279-292.

JózAN, Zs. 1998: A Duna-Dráva Nemzeti Park fullánkos hártyásszárnyú (Hymenoptera, Aculeata) faunája. Dunántúli Dolgozatok Természettudományi Sorozat 9: 291-327.

JózAN, Zs. 2000a: Újabb adatok a Bakony kaparódarázs faunájának (Hymenoptera, Sphecoidea) ismeretéhez. - Folia Musei Historico-Naturalis Bakonyiensis 15(1996): 101-124.

JózAN, Zs. 2000b: Külső-Somogy méhszerü (Hymenoptera, Apoidea) faunája. - Somogyi Múzeumok Közleményei 14: 307-330.

JózAN, Zs. 2002: Az Örség és környéke fullánkos hártyásszárnyú faunájának alapvetése (Hymenoptera, Acuelata). - Praenorica Folia Historico-Naturalia 6: 59-96.

Józan, Zs. 2011: Checklist of Hungarian Sphecidae and Apidae species (Hymenoptera, Sphecidae and Apidae). - Natura Somogyiensis 19: 177-200.

JózAN, Zs. 2006: A Mecsek fullánkos hártyásszárnyú faunája (Hymenoptera, Aculeata). - Folia Comloensis 15: 219-238.

JózAN, Zs. 2018: Újabb adatok Somogy megye fullánkos hártyásszárnyú (Hymenoptera: Aculeata) faunájához. - Natura Somogyiensis 32: 133-146.

Kovács, T 2015: Megachile sculpturalis Smith, 1853 in Hungary. - Folia Historico-Naturalia Musei Matrensis 39: $73-76$.

MóczÁr, M. 1956: A pelyhesméhek (Anthidium Fabr.) faunakatalógusa és etológiai adatai (Cat. Hym. IX.). - Folia Entomologica Hungarica IX/11: 211-222.

MóczÁr, M. 1958: Mủvészméhek - Megachilidae - in: Magyaroszág Állatvilága (Fauna Hungariae) XIII/12: $1-78$.

MóczÁr, L. \& Schwarz, M. 1968: A Nomada-, Ammobates-, Pasites- és Parammobatodes nemek faunakatalógusa (Cat. Hym. XXIII.) - Folia Entomologica Hungarica XXI/23: 339-360.

Tanács, L. \& Józan, Zs. 1993: The Apoidea fauna oft the Bükk National Park. - In Mahunka, S. (ed.): The Fauna of the Bükk National Park, I. - Természettudományi Múzeum Budapest, 423-444.

VAS, Z. \& JÓZAN, Zs. 2014: Új adatok és határozókulcs Magyarország lopódarázs faunájához (Hymenoptera: Sphecidae). - Natura Somogyiensis 24: 157-164. 